\title{
High throughput screening of photocatalytic conversion of pharmaceutical contaminants in water
}

Citation for published version (APA):

Romao, J., Barata, D., Ribeiro, N., Habibovic, P., Fernandes, H., \& Mul, G. (2017). High throughput screening of photocatalytic conversion of pharmaceutical contaminants in water. Environmental Pollution, 220, 1199-1207. https://doi.org/10.1016/j.envpol.2016.11.015

Document status and date:

Published: 01/01/2017

DOI:

10.1016/j.envpol.2016.11.015

Document Version:

Publisher's PDF, also known as Version of record

Document license:

Taverne

Please check the document version of this publication:

- A submitted manuscript is the version of the article upon submission and before peer-review. There can be important differences between the submitted version and the official published version of record.

People interested in the research are advised to contact the author for the final version of the publication, or visit the DOI to the publisher's website.

- The final author version and the galley proof are versions of the publication after peer review.

- The final published version features the final layout of the paper including the volume, issue and page numbers.

Link to publication

\footnotetext{
General rights rights.

- You may freely distribute the URL identifying the publication in the public portal. please follow below link for the End User Agreement:

www.umlib.nl/taverne-license

Take down policy

If you believe that this document breaches copyright please contact us at:

repository@maastrichtuniversity.nl

providing details and we will investigate your claim.
}

Copyright and moral rights for the publications made accessible in the public portal are retained by the authors and/or other copyright owners and it is a condition of accessing publications that users recognise and abide by the legal requirements associated with these

- Users may download and print one copy of any publication from the public portal for the purpose of private study or research.

- You may not further distribute the material or use it for any profit-making activity or commercial gain

If the publication is distributed under the terms of Article $25 \mathrm{fa}$ of the Dutch Copyright Act, indicated by the "Taverne" license above, 


\title{
High throughput screening of photocatalytic conversion of pharmaceutical contaminants in water ${ }^{\text {th }}$
}

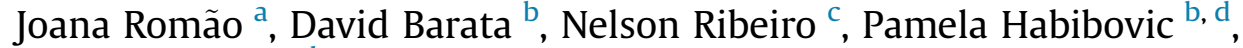 \\ Hugo Fernandes ${ }^{\text {b, e, * , Guido Mul }}{ }^{\text {a, ** }}$ \\ a Photocatalytic Synthesis Group, MESA+ Institute for Nanotechnology, Faculty of Science and Technology, University of Twente, Meander 229, P.O. Box 217, \\ 7500 AE, Enschede, The Netherlands \\ ${ }^{\mathrm{b}}$ MIRA Institute for Biomedical Technology and Technical Medicine, University of Twente, P.O. Box 217, 7500 AE, Enschede, The Netherlands \\ ${ }^{\mathrm{C}}$ LAETA, IDMEC, Instituto Superior Técnico, Universidade de Lisboa, Portugal \\ ${ }^{\mathrm{d}}$ Maastricht University, MERLN Institute for Technology-Inspired Regenerative Medicine, P.O. Box 616, 6200 MD, Maastricht, The Netherlands \\ e Stem Cells and Drug Screening Lab, Center for Neuroscience and Cell Biology, University of Coimbra, Coimbra, Portugal
}

\section{A R T I C L E I N F O}

\section{Article history:}

Received 29 June 2016

Received in revised form

4 November 2016

Accepted 5 November 2016

Available online 10 November 2016

\section{Keywords:}

High throughput screening

Pharmaceutical compounds

Photocatalysis

Titanium dioxide

Water treatment

Reactant selectivity

\begin{abstract}
A B S T R A C T
The susceptibility for photon-induced degradation of over 800 pharmaceutical compounds present in the LOPAC ${ }^{1280}$ library, was analyzed by UV/Vis spectroscopy in the absence or presence of $\mathrm{TiO}_{2} \mathrm{P} 25$ in water. In general, few compounds were effectively degraded in the absence of the $\mathrm{TiO}_{2}$ photocatalyst $(3 \%$ of all compounds tested), while in the presence of $\mathrm{TiO}_{2}$, the majority of compounds was converted, often to a large degree. Differences in degree of degradation are evaluated on the basis of molecular weight, as well as the chemical nature of the drug compounds (functional groups and pharmacological classes). In general, if the molecular weight increases, the degradation efficacy decreases. Relatively high degrees of conversion can be achieved for (relatively small) molecules with functional groups such as aldehydes, alcohols, ketones and nitriles. A low degree of conversion was observed for compounds composed of conjugated aromatic systems. Trends in degradation efficacy on the basis of pharmacological class, e.g. comparing hormones and opioids, are not obvious.
\end{abstract}

๑) 2016 Elsevier Ltd. All rights reserved.

\section{Introduction}

The increase in concentration of emerging contaminants in waste water (pharmaceuticals, metabolites, endocrine-disrupting drugs) raises health concerns, and might disturb the general balance of the ecosystem (Halling-Sorensen et al., 1998; Hernando et al., 2006). Caffeine, codeine, naproxen, acetaminophen, diclofenac, ofloxacin and ibuprofen, have been reported to be present in surface and ground water in the range of a few $\mathrm{ng} \mathrm{L}^{-1}$ to a few $\mathrm{mg} \mathrm{L}^{-1}$ (Bueno et al., 2012; Fatta-Kassinos et al., 2011). Standard wastewater treatment, either chemical or biological, is unable to completely degrade these emerging contaminants (Joss et al., 2006; Radjenovic et al., 2008). Advanced oxidative processing (AOP)

\footnotetext{
th This paper has been recommended for acceptance by Charles Wong.

* Corresponding author. MIRA Institute for Biomedical Technology and Technical Medicine, University of Twente, P.O. Box 217, 7500 AE, Enschede, The Netherlands. ** Corresponding author.

E-mail addresses: fernandesham@gmail.com (H. Fernandes),g.mul@utwente.nl (G. Mul).
}

eliminates some of these compounds from water, making use of the in situ generation and subsequent reaction of (unselective) hydroxyl radicals $\left(\mathrm{HO}^{\bullet}\right.$ ) (Hoffmann et al., 1995; Lee and Park, 2013). The disadvantage of this technology is that sacrificial agents, such as iron salts and/or hydrogen peroxide, are needed (Lee and Park, 2013). Heterogeneous photocatalysis can also induce complete mineralization of organic contaminants to $\mathrm{CO}_{2}$ and $\mathrm{H}_{2} \mathrm{O}$ (Spasiano et al., 2015). Decomposition in such process is achieved through the generation of intermediary oxidative species $\left(\mathrm{HO}^{\bullet}, \mathrm{O}_{2}^{\bullet-}\right)$, created by reduction of oxygen and oxidation of water by electronhole pairs, formed when a semiconductor $\left(\mathrm{ZnO}, \mathrm{WO}_{3}\right.$, or $\left.\mathrm{TiO}_{2}\right)$ is exposed to light (Hoffmann et al., 1995). Photocatalysis is considered highly sustainable, and the fact that the technology does not require sacrificial agents or high pressure or temperature, but only an environmentally benign, cheap semiconductor $\left(\mathrm{TiO}_{2}\right)$, makes it very attractive. Titanium dioxide $\left(\mathrm{TiO}_{2}\right)$ is the most effective photocatalyst for water treatment applications so far described, particularly due to its high stability in water (Chong et al., 2010).

Photocatalysis approaches have previously been evaluated for removal of organic compounds from water, such as dyes, phenols 


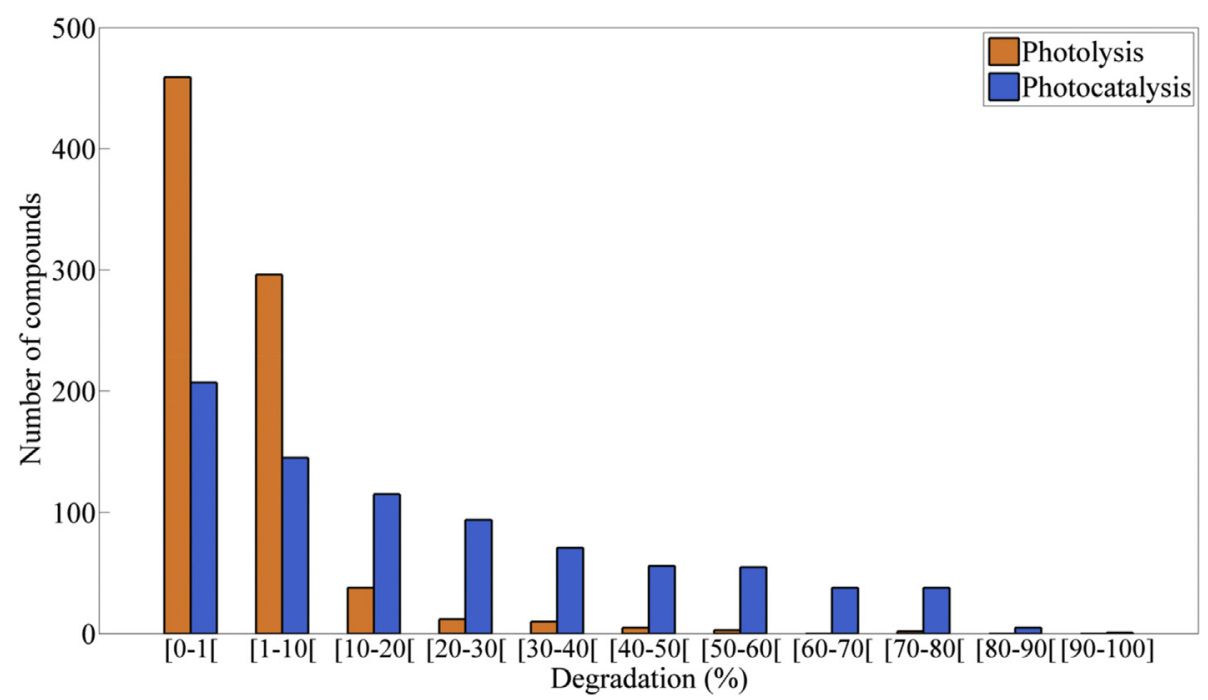

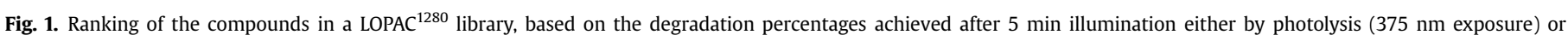
photocatalysis (375 $\mathrm{nm}$ exposure, $\mathrm{TiO}_{2} \mathrm{P} 25$ ).

and pharmaceuticals (diclofenac, naproxen) (Ahmed et al., 2011; Dalrymple et al., 2007; Malato et al., 2007). However, to the best of our knowledge, little is known about the degradation mechanism of these compounds and which specific molecular functionality enhances the susceptibility to photocatalytic degradation.

High throughput screening (HTS) is a powerful tool to evaluate the degradation probability of a wide variety of drug-related compounds, and to help identify whether this probability is a function of specific functionality in the molecular structure. Two analytical methods were previously used for combinatorial screening of photocatalytic degradation: the first is High Performance Liquid Chromatography (HPLC) (Lettmann et al., 2001), used in evaluation of the decomposition of 4-chlorophenol, and the second fluorescence imaging, used for study of the decomposition

Table 1

Comparison of selected compounds in photolytic or photocatalytic degradation percentages.

\begin{tabular}{|c|c|c|}
\hline Compounds & Photolysis degradation (\%) & Photocatalytic degradation (\%) \\
\hline $\mathrm{O}$ & 76 & 80 \\
\hline \multicolumn{3}{|c|}{ TCPOBOP } \\
\hline \multicolumn{3}{|c|}{ SIB 1893} \\
\hline & 57 & 83 \\
\hline \multicolumn{3}{|c|}{ SB-366791 } \\
\hline $\mathrm{OH}$ & 6 & 63 \\
\hline & & \\
\hline
\end{tabular}




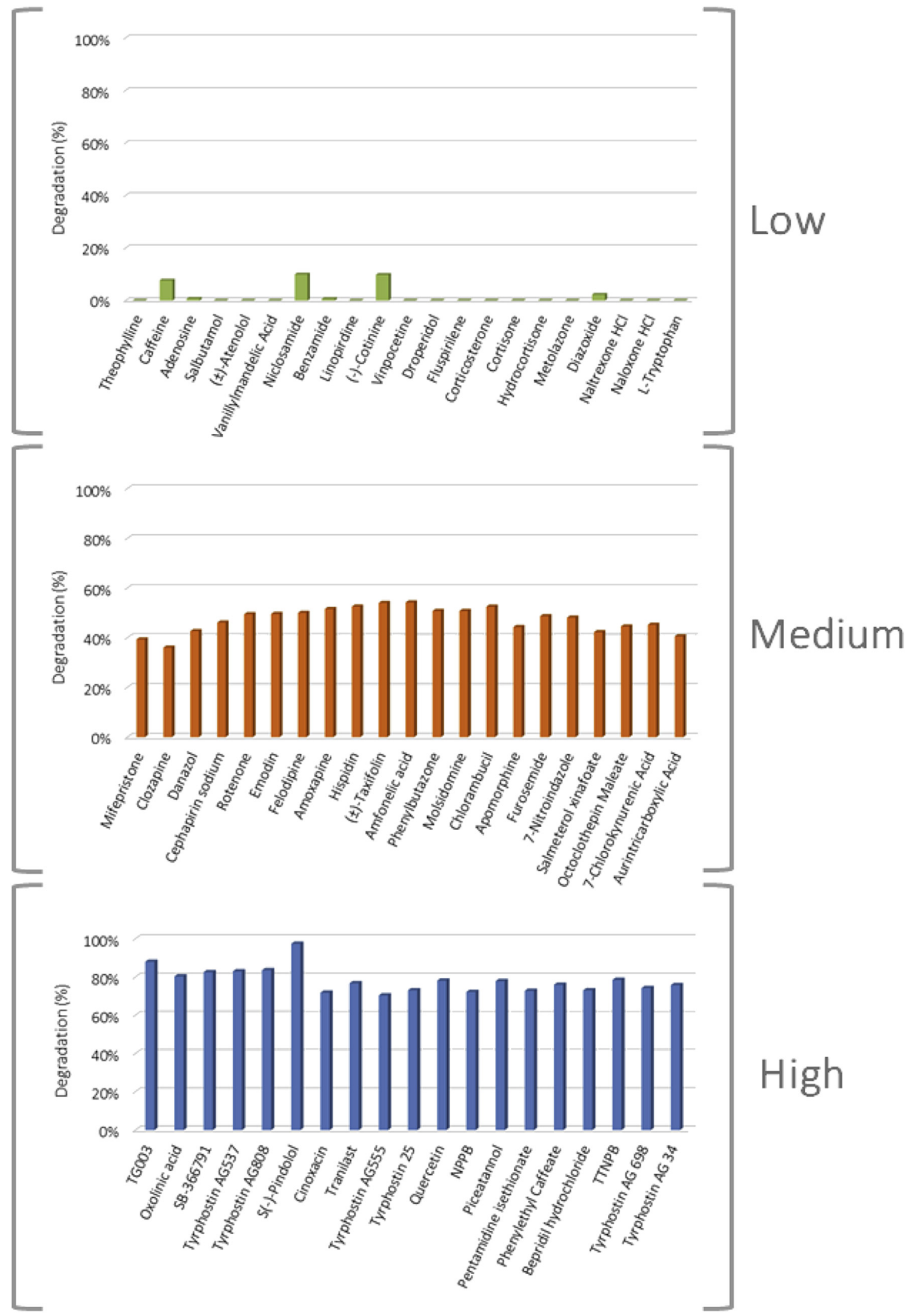

Fig. 2. Photocatalytic degradation percentages achieved for some of the most representative compounds in LOPAC ${ }^{1280}$.

of 1,6-hexamethylenediamine (Xiao et al., 2006). One of the most elaborate studies reported to date describes the substrate-specific activity of eight commercial $\mathrm{TiO}_{2}$ samples to decompose 19 different substrates (Ryu and Choi, 2007).

In this work we describe, for the first time, a HTS assay to study oxidative photodegradation efficacy of compounds present in a 
Table 2

Compounds with similar chemical functionality and the respective degradation percentages. The similarity results suggests consistency of the 96-well plate method.

\begin{tabular}{|c|c|c|c|c|c|}
\hline Compounds & $\begin{array}{l}\text { Degradation } \\
(\%)\end{array}$ & Compounds & $\begin{array}{l}\text { Degradation } \\
(\%)\end{array}$ & Compounds & $\begin{array}{l}\text { Degradation } \\
(\%)\end{array}$ \\
\hline & 0 & & 17 & & 75 \\
\hline
\end{tabular}

(-)-alpha-Methylnorepinephrine<smiles>CC12CCC(=O)C=C1CCC1C2C(O)CC2(C)C(C(=O)CO)CCC12</smiles>

Corticosterone<smiles>NCC(O)c1ccc(O)c(O)c1</smiles>

$( \pm)$-Norepinephrine $(+)$ bitartrate
Tyrphostin 23

18<smiles>N#CC(C#N)Cc1cc(O)c(O)c(O)c1</smiles>

Tyrphostin 25
LOPAC $^{1280}$ library, which is a library of 1280 pharmacologically active compounds divided in drug target classes, such as hormones and neurotransmitters. A miniaturized microplate photo-reactor, in combination with a UV-Vis microplate spectrometer were used for analysis, as described previously by Romão and coworkers (Romão et al., 2015). Although visible light sensitive catalysts exist, such as $\mathrm{BiVO}_{4}$ or $\mathrm{WO}_{3}$, the efficacy is typically significantly smaller than of $\mathrm{TiO}_{2}-\mathrm{P} 25$ upon UV excitation. $\mathrm{TiO}_{2}-\mathrm{P} 25$ was therefore chosen as photocatalyst, which also allows for a better comparison with existing literature.

\section{Materials and methods}

\subsection{Materials}

To evaluate the ability of photocatalysis to oxidize pharmaceutical compounds, a LOPAC ${ }^{1280}$ library was used, obtained from Sigma Aldrich. LOPAC ${ }^{1280}$ is a library of pharmacologically active compounds dissolved in dimethyl sulfoxide (DMSO), comprising FDA-approved molecules and other drugs used in industrial processes, thus making it a very suitable for the purpose of this study. Evonik $\mathrm{TiO}_{2} \mathrm{P} 25$ was used as the photocatalyst, and used without modification.

\subsection{Microplate photo-reactor setup for LOPAC ${ }^{1280}$ screening}

The experimental setup used for determination of photocatalytic efficacy was described and validated previously (Romao et al., 2014). To initiate a photon-induced degradation experiment, the LOPAC ${ }^{1280}$ library was distributed over sixteen 96-well plates (concentration of $2000 \mu \mathrm{M}$ ). In the absence of catalyst, $25 \mu \mathrm{L}$ of the library solutions were diluted in demineralized water to reach the final working volume of $200 \mu \mathrm{L}$ (final concentration $25 \mu \mathrm{M}$ ) in UV transparent 96-well microplates (Corning). To evaluate photocatalytic efficacy, an aqueous slurry of $\mathrm{TiO}_{2}$ P25 at $0.25 \mathrm{~g} \mathrm{~L}^{-1}$ was prepared and transferred in equal volumes $(192.4 \mu \mathrm{L} /$ well) to the 96 -well plates, followed by the addition of $27.6 \mu \mathrm{L}$ from the LOPAC ${ }^{1280}$ stock solution, resulting in a final working volume of $220 \mu \mathrm{L}$ (final concentration of $25 \mu \mathrm{M}$ ). The concentration of the compounds in the library was thus typically in the range of $1.1-37.6 \mathrm{mg} / \mathrm{L}$. We like to stress that in urban wastewater effluents, antibiotics such as ibuprofen, metronidazole and atenolol were found at the respective concentrations of $0.15,0.09$ and $0.12 \mathrm{mg} / \mathrm{L}$
(Fatta-Kassinos et al., 2011), significantly lower than applied here. The (equimolar $25 \mu \mathrm{M}$ ) concentration range of $1.1-37.6 \mathrm{mg} / \mathrm{L}$ was chosen on the basis of the detection limit of the UV spectrometric method.

In both experimental conditions (photolysis and photocatalysis), the 96-well plates were illuminated from the top with a multitubular light source at a distance of $5 \mathrm{~cm}\left(3.21 \mathrm{~mW} \mathrm{~cm}^{-2}\right.$, $360-380 \mathrm{~nm}$ ) for $5 \mathrm{~min}$. In the case of the photocatalytic experiment, the aqueous suspension was transferred into a 96-well filter microplate (Corning, hydrophilic $0.2 \mu \mathrm{m}$ PVDF membrane) and the solution filtered into a new 96 -well microplate by centrifugation at $300 \mathrm{rpm}$ for $3 \mathrm{~min}$ in order to separate-off the photocatalyst. Afterwards, just $200 \mu \mathrm{L}$ was transferred into a new UV transparent 96-well microplate (Corning). This guarantees an equal volume per well and the same path length, $l$, required for proper application of the Lambert-Beer law $(A=\varepsilon . l . c)$ when using the microplate spectrophotometer (Multiskan ${ }^{\mathrm{TM}} \mathrm{GO}$, Thermo Scientific). Measurements were processed and used to assess the degradation profile of each compound, in each well, through the intensity decrease in absorbance spectra (at peak value). Previous to any reaction, the maximum in the absorbance spectrum for each compound was determined in the spectral range of $200-800 \mathrm{~nm}$, and used for concentration determination (the spectrum of DMSO in water was used as background).

\subsection{Data analysis}

The spectral data obtained (photolysis and photocatalytic degradation) for each compound of the LOPAC ${ }^{1280}$ library were saved into a spreadsheet forming a dataset. Afterwards, information about the molecular weight, pharmacological class and functional groups was gathered and stored for all compounds. For data handling and further processing, the dataset was imported into MATLAB, used for clustering and extraction of relevant information. Series of scripts were therefore created to cover data mining steps involving data pre-processing, management and visualization (bar graphs, scatter and box plots).

\section{Results and discussion}

\subsection{Photolysis vs photocatalysis}

Prior to the determination of the photo (catalytic) conversion 


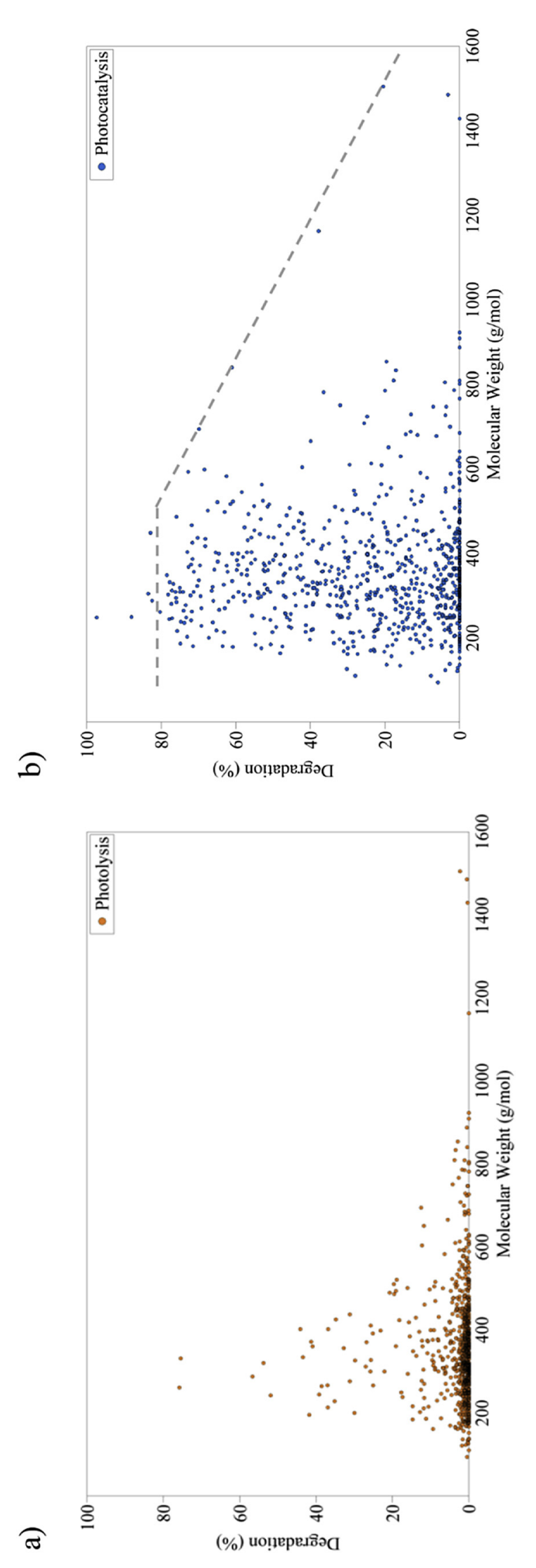

efficiency, UV-Vis spectra of the 1280 compounds were measured. Several compounds had to be excluded from the study, since they did not show any UV/Vis absorption peak. From the initial 1280 compounds, 825 compounds were found suitable for further analysis. Other methods, such as LC-MS, should be used to study the degradation rate of the other 455 compounds, but such analysis is hard to conduct in a combinatorial fashion. An overview of the results for the 825 compounds from LOPAC ${ }^{1280}$ is shown in Fig. 1. $\mathrm{TiO}_{2} \mathrm{P} 25$ induced photocatalysis is clearly superior over photolysis, showing a significantly higher number of compounds with high degradation percentages. Photolysis could only decompose few compounds up to degradation efficiencies of $40 \%$ (5), $50 \%$ (3) and $70 \%(2)$.

In Table 1, some of the few compounds showing high degradation percentages solely by photolysis are highlighted. Notably, the degradation of these compounds (oxolinic acid, TCPOBOP, Molsidomine, SIB 1893 and SB-366791) was not significantly higher in the presence of the photocatalyst. A common feature of the compounds decomposed merely by photolysis, is the presence of benzene and pyridine rings, apparently yielding compounds susceptible to oxidation upon photo-activation. Certainly the efficacy in photochemical degradation will be higher for most compounds when lower excitation wavelengths than $360-380 \mathrm{~nm}$ would have been used. Oxolinic Acid has an absorption maximum at $366 \mathrm{~nm}$, which explains the high photochemical degradation percentage.

For the large majority the presence of $\mathrm{TiO}_{2} \mathrm{P} 25$ significantly increases the percentage of degradation, such as of Apigenin (Table 1).

Fig. 2 shows the respective photocatalytic degradation percentages of a large set of selected compounds from the LOPAC ${ }^{1280}$ library. The results are categorized by High, Medium and Low levels of degradation (after 5 min of illumination). In the group of a low degree of degradation are compounds such as caffeine, adenosine and cortisone, while in the group of a high degree of degradation are (S)-pindolol and several compounds from the tyrphostin family (drugs that inhibit enzymes responsible for the activation of certain proteins). The high reproducibility of the screening method is confirmed by the results shown in Table 2: compounds with similar chemical backbone tend to have similar degradation values in photocatalysis.

\subsection{Molecular weight (MW)-dependent degree of conversion}

Fig. 3 shows an attempt to correlate the MW of the substrate and the percentage of degradation, both in photolysis and photocatalysis configuration. As previously observed, in photolysis a lower degree of degradation is predominant. In Fig. 3.b, a decreasing trend in maximum degradation rates seems to be present as a function of increasing MW. Nevertheless a relation between MW and degradability of the organic molecules is not obvious. Only above $500 \mathrm{~g} \mathrm{~mol}^{-1}$ the maximum achievable percentage is significantly lower. For compounds with a MW around $250 \mathrm{~g} \mathrm{~mol}^{-1}$ up to $97 \%$ degradation was frequently achieved, whereas molecules with a MW higher than $500 \mathrm{~g} \mathrm{~mol}^{-1}$ show lower (maximum) values. This is in agreement with the perception that more time is needed to break and oxidize all the chemical bonds. Table 3 highlights a few organic compounds with different MW and their corresponding decomposition percentage. On the basis of these data, the dashed gray line in Fig. 3.b was drawn, reporting the local maxima. Table 3 clearly shows that when the MW increases, the complexity in the chemical backbone also increases, which likely contributes to the fact that degradation becomes more difficult. Another important factor is derived from the interaction between the compounds with the catalyst surface that 
Table 3

Compounds with different MWs and their degradation percentages.

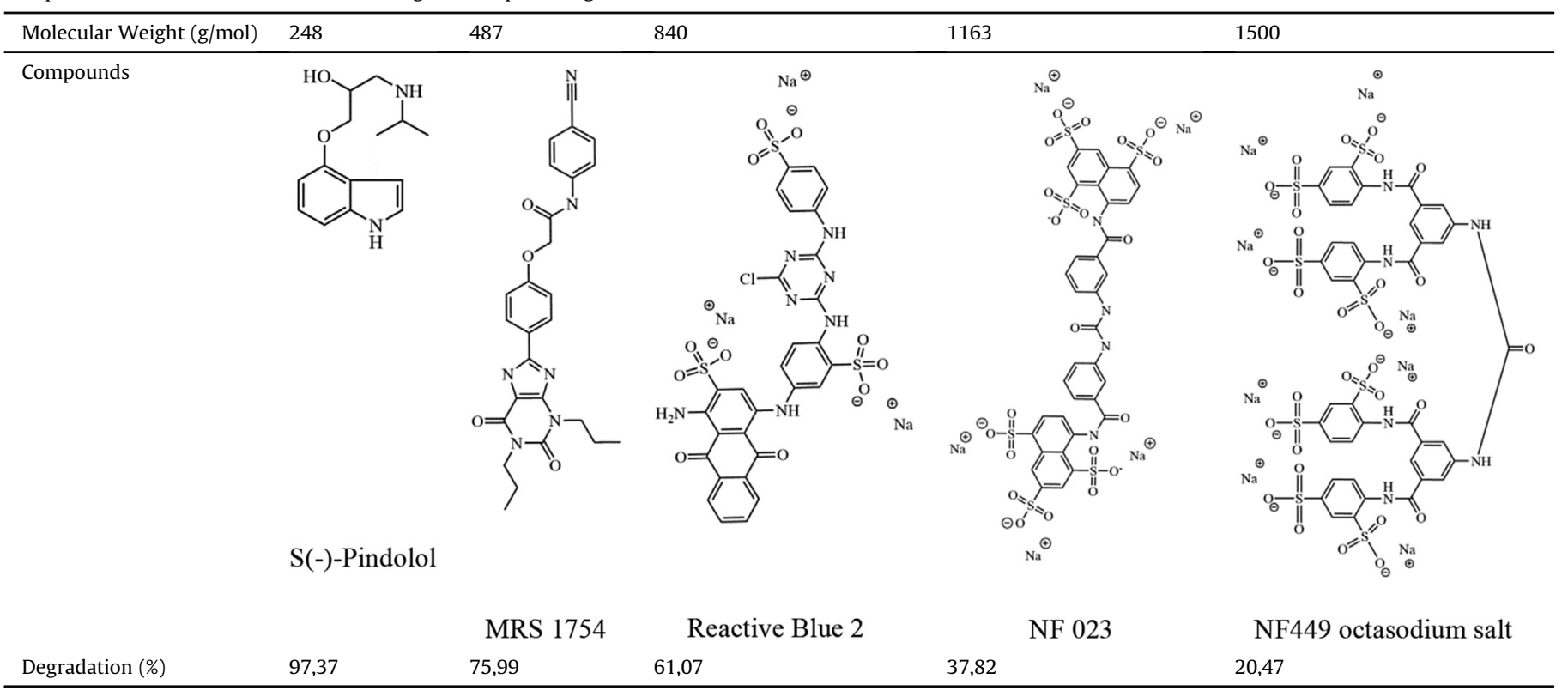

can be affected by the molecular structure flexibility/rigidity which increases with increasing MW.

\subsection{Pharmacological classes}

The LOPAC library can be divided in drug target classes, e.g., GPCRs ( $G$ protein-coupled receptors), ligands, hormones and neurotransmitters. Neurotransmitters can again be subdivided in other classes, such as adenosine, adrenoceptors, histamine, imidazoline, and opioids, among others (Sigma-Aldrich). Fig. 4 shows degradation percentages organized by pharmacologically active classes. In this Figure, central values (vertical black line which indicates the mean) never exceed degradation percentages above $10 \%$ for photolysis. Leukotriene and melatonin stand out for their relatively high degradation values, when compared to other compounds. The leukotriene class does not have a characteristic chemical group, but includes benzene, ester, amine and carboxylic acid functionality.

On the other hand, the compounds within the melatonin class usually have indole (benzene and pyrole rings) and amide groups, suggesting that these are susceptible to oxidation upon light activation.

Histamine, imidazoline, GABA and opioids are the least susceptible to photocatalytic degradation. The histamine class covers derivatives from imidazole with a side-chain amine, similar to

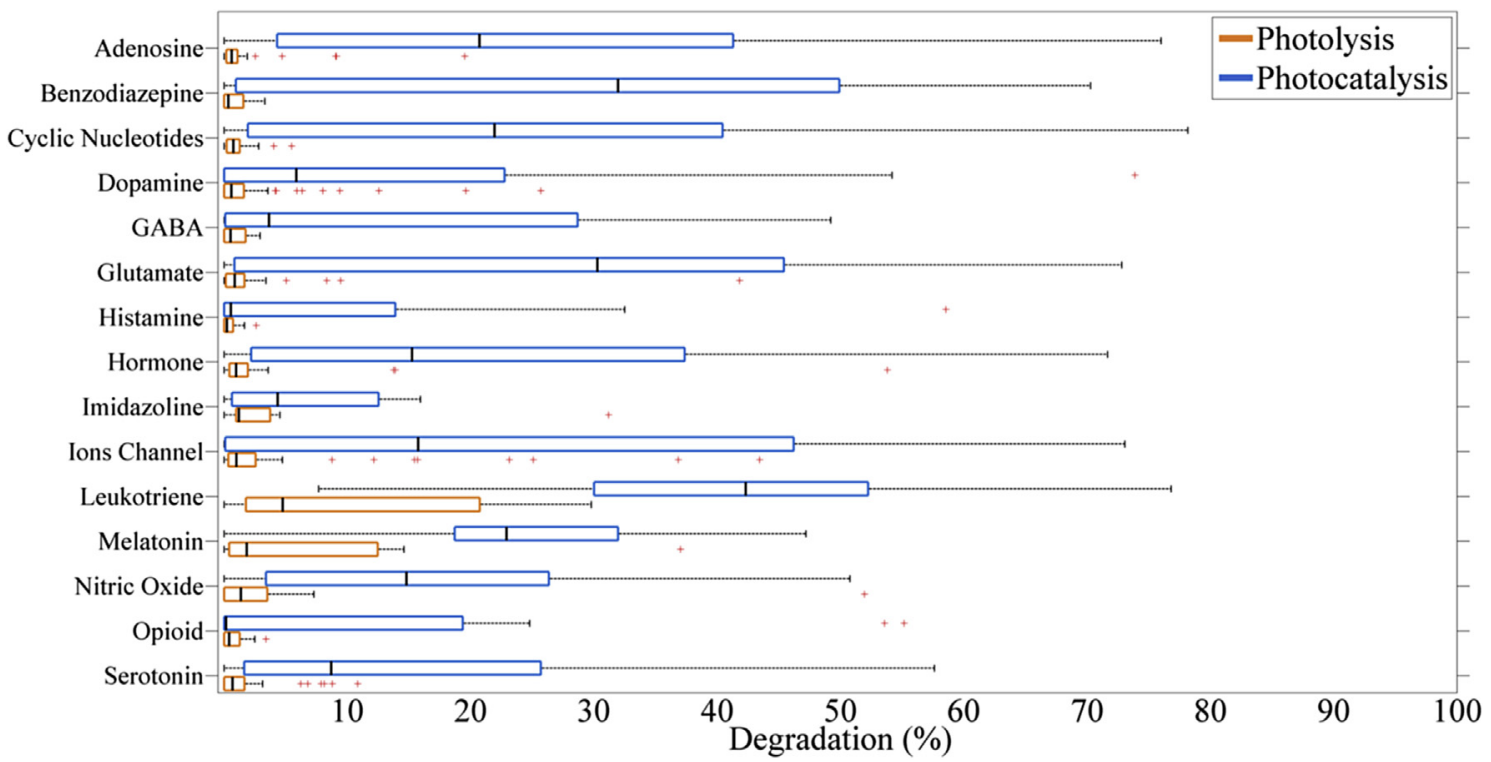

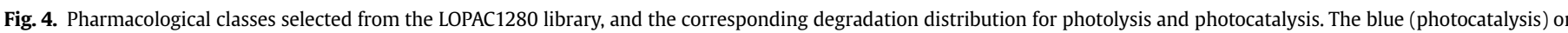

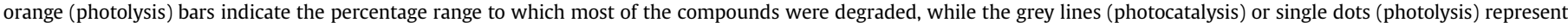

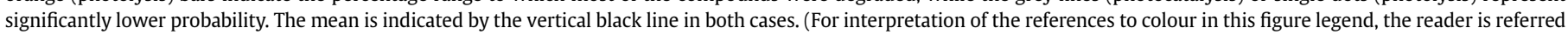
to the web version of this article.) 
Naloxone Hydrochloride

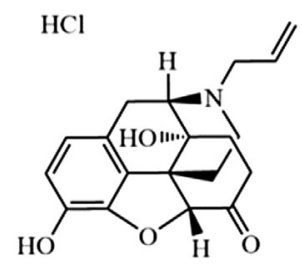

$0 \%$
Naloxone benzoylhydrazone

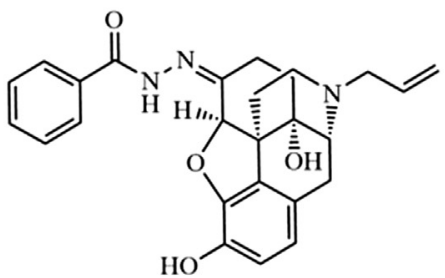

$54 \%$
Naltriben Methanesulfonate

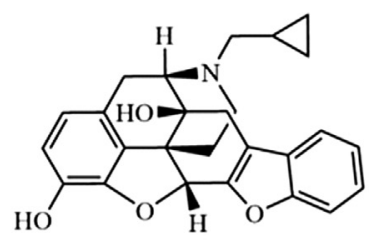

$55 \%$

Degradation Percentage

Fig. 5. Compounds from the opioid class and the corresponding degradation percentages achieved by photocatalysis.

many derivatives from this family present in the library. A salt of histamine (histamine dihydrochloride) was not degraded, and a similar compound, 4-Imidazoleacrylic acid, undergoes only $2 \%$ of degradation. Imidazolines, the name given to the derivatives of imidazole, also showed very low degradation percentages (Fig. 4). The Imidazole molecule is difficult to be oxidized or, at least, demands more reaction time for dis-colorization. The compounds included in the opioid class resemble morphine, containing aromatic rings and a quaternary carbon atom bound to a tertiary amine group linked to two carbon atoms. This class also shows a very low degradation percentage, as show in Fig. 4. Naloxone hydrochloride, naltrexone hydrochloride, levallorphan tartrate which have a very similar chemical structure to morphine, showed hardly degradation. Higher degradation percentages were obtained for naloxone benzoylhydrazone and naltriben methanesulfonate, which might be ascribed to the presence of an additional phenyl group or an azo bond $(\mathrm{N}=\mathrm{N})$. The oxidation reaction might be initiated by the activation of these groups (Fig. 5).

It has been described that morphine can be completely mineralized by photocatalysis (Lin et al., 2013), however the concentration used was $3.5 \mu \mathrm{M}$. In the present screening study, the concentration was significatively higher, at $25 \mu \mathrm{M}$. The fact that other opioids, such as naltriben methanesulfonate could be mineralized by $50 \%$, confirms that this class is suitable for degradation by photocatalysis.

The adenosine class includes, as the name implies, adenosine, adenine, or caffeine molecules, and derivatives thereof. From this class, $82 \%$ of the compounds showed a degradation percentage below $50 \%$. Theobromine is an exception, and $71 \%$ conversion was reached. Caffeine is a compound present at high concentrations in sewage and it has been reported that its complete mineralization is difficult to achieve (Carotenuto et al., 2014; Matsuo et al., 2004), which is confirmed by the results obtained in our study.

The Adrenoceptor class comprises compounds such as epinephrine (adrenaline) and norepinephrine (noradrenaline), which consists of a 1,2-dihydroxybenzene molecule with a sidechain amine and derivatives. In the case of adrenaline and noradrenaline, the degradation percentages achieved were respectively 3 and 18\%, showing potential for degradation by photocatalysis. In the literature the photocatalytic degradation reported for a compound from the same class, atenolol, is 10\% (Ji et al., 2013), in agreement with the percentage range obtained in the present study.

Hormones comprise another class of compounds represented in LOPAC $^{1280}$, including molecules from the corticosteroids family (compounds with three to six-carbon rings combined with a fivecarbon ring). Examples of this are corticosterone, cortisone, and hydrocortisone, among others. However, while these were not degraded, other steroid hormones such as progesterone and 4Androsten-4-ol-3,17-dione yielded degradation percentages of $32 \%$ and $58 \%$, respectively. Fig. 6 shows that this class of compounds can be degraded by photocatalysis and that small differences in the functional groups can affect the degradation percentages observed. A derivative of cortisone, cortisone-acetate, can be degraded by this method, however to fully mineralize this compound with a concentration of $25 \mu \mathrm{M}, 90$ min of illumination were necessary (Romão

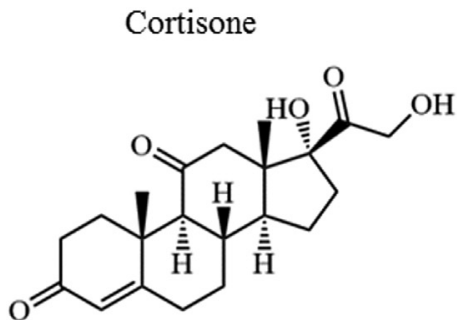

$0 \%$
Progesterone

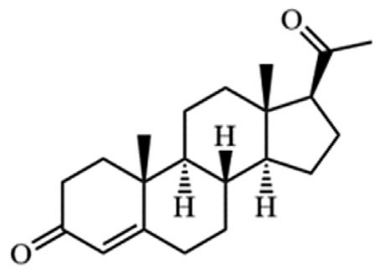

$32 \%$
4-Androsten-4-ol-3,17-dione<smiles>CC1(C)CC[C@H]2[C@H]1CCC1=C(O)C(=O)CC[C@@]12C</smiles>

$58 \%$

Fig. 6. Compounds belonging to the corticosteroids family and their corresponding degradation percentages achieved by photocatalysis. 


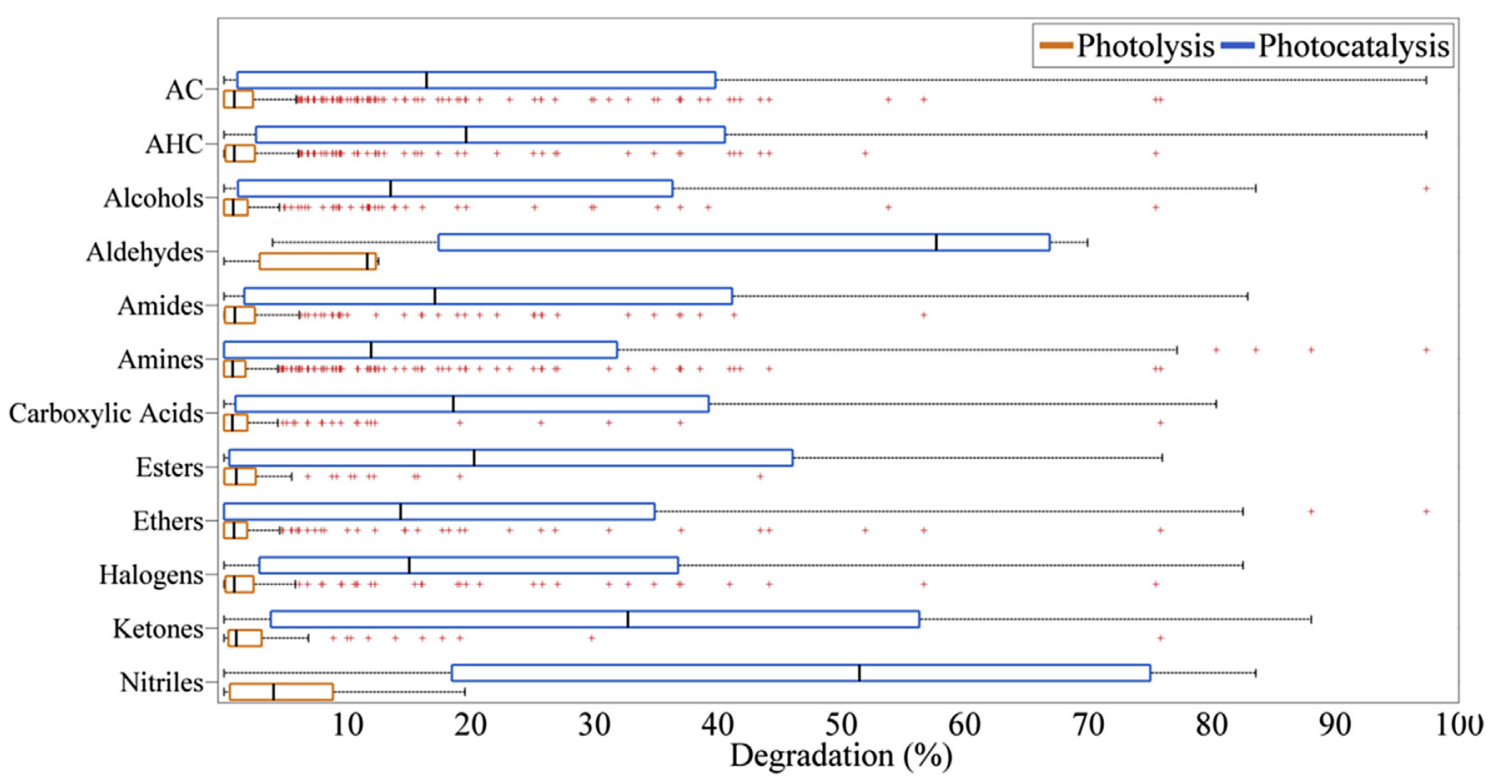

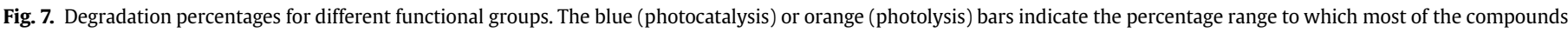

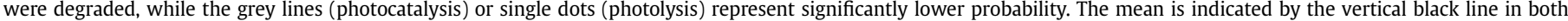
cases. (For interpretation of the references to colour in this figure legend, the reader is referred to the web version of this article.)

\section{et al., 2015).}

Melatonin and derivatives thereof, were relatively easy to degrade. This class of compounds has a specific chemical group, being an indole molecule with a side-chain amide. Likely, these groups contribute to relatively easy oxidation (Merabet et al., 2009).

It should be noticed that not all the classes present in the LOPAC $^{1280}$ library are necessarily associated with (a) specific chemical group(s) or backbone unit, but rather categorized by its biological functionality. Therefore, further analysis is done targeting the effect of the chemical nature of the compounds used in this study.

\subsection{Further focus on functional groups}

Each compound from the LOPAC ${ }^{1280}$ library was characterized by its intrinsic chemical nature, considering its structural composition and chemical bonds. The functional groups considered were: aromatic cyclic (AC) compounds, aromatic heterocyclic (AHC) compounds, alcohols, aldehydes, amides, amines, carboxylic acid, esters, ether, halogens, ketones and nitriles. Fig. 7 shows an elaborated view of the degradation percentages on the basis of these functional groups.

For various functional groups, the range in degradation percentage is broad, but we still find the difference in mean (average) degradation percentage for various functional groups significant, providing interesting leads in particular for substrate susceptibility towards $\mathrm{TiO}_{2}$ induced photocatalytic conversion. There are some functional groups that show relatively high susceptibility for degradation: aldehydes, ketones and nitriles. Looking at the compounds included in the aromatic heterocyclic (AHC) group, indole molecules stand out, which is in agreement with the results found for the melatonin class.

Finally, in order to understand why 207 compounds (Fig. 1) were not degraded, their chemical structure was evaluated in more detail. Overall, these molecules contain cyclic aromatic compounds and are derivatives of purine, caffeine, pyrimidine, pyridine and imidazoline.
To explain differences in susceptibility of compounds for photocatalytic degradation, some aspects of the mechanism of photocatalytic degradation should be considered. When the oxidation mechanism involves reaction of the substrates with dissolved hydroxyl radicals, (generated upon light activation on the surface of $\mathrm{TiO}_{2}$, followed by desorption), little effect of the functional groups can be expected. However, an alternative mechanism involves adsorption of molecules on the surface of $\mathrm{TiO}_{2}$, followed by direct transfer of photo-generated holes to the adsorbed molecules. It is well known that susceptibility for adsorption on oxide surfaces is very much dependent on functional groups of molecules, and the difference in observed reactivity might be associated with such adsorption-based mechanism.

The results presented here should be considered preliminary. Obviously, the kinetics and formation of intermediates in the degradation process are relevant and need to be studied in more detail, especially as a function of process conditions. Comparing degradation kinetics of molecules with large molecular mass at longer degradation times, should also be performed, to identify intermediate products and degradation pathways. To this end, the use of analytical techniques, such as HPLC in combination with MS is viable. We also recommend future study of the eco-toxicity of the compounds of the library, to determine urgency of mitigation. Finally the eco-toxicity of partially oxidized intermediates (if any) should be considered, which might be even more toxic than the undegraded pharmaceutical compounds.

\section{Conclusions}

This study evaluates the applicability of $\mathrm{TiO}_{2} \mathrm{P} 25$, by far the most used photocatalyst, to eliminate new emerging contaminants from wastewater, included in the LOPAC ${ }^{1280}$ library.

High degradation efficiencies were obtained for molecules with functional groups such as aldehydes, alcohols, ketones, nitriles, and amides. Indole derived molecules were particularly susceptible towards photocatalytic degradation. Compounds with conjugated aromatic systems, and derivatives from compounds such as adenosine, caffeine and imidazole, were relatively difficult to convert by 
$\mathrm{TiO}_{2}$-based photocatalysis and showed low degradation values.

UV-Vis spectrometry provides and easy, fast and reliable quantification method. However, it does not allow to follow intermediates or confirm if the molecules were completely converted into $\mathrm{CO}_{2}$ and $\mathrm{H}_{2} \mathrm{O}$ (and Nitrate). This requires more elaborate study and analysis by e.g. HPLC-MS.

\section{Acknowledgments}

This work was supported by NanoNextNL, a micro and nanotechnology consortium of the Government of the Netherlands and 130 partners. HF was partially funded by COMPETE in the context of the project "Stem cell based platforms for Regenerative and Therapeutic Medicine" (Centro-07-ST24-FEDER-002008).

\section{References}

Ahmed, S., Rasul, M.G., Martens, W.N., Brown, R., Hashib, M.A., 2011. Advances in heterogeneous photocatalytic degradation of phenols and dyes in wastewater: a review. Water, Air, Soil Pollut. 215, 3-29.

Bueno, M.J.M., Gomez, M.J., Herrera, S., Hernando, M.D., Aguera, A., FernandezAlba, A.R., 2012. Occurrence and persistence of organic emerging contaminants and priority pollutants in five sewage treatment plants of Spain: two years pilot survey monitoring. Environ. Pollut. 164, 267-273.

Carotenuto, M., Lofrano, G., Siciliano, A., Aliberti, F., Guida, M., 2014. TiO 2 photocatalytic degradation of caffeine and ecotoxicological assessment of oxidation by-products. Glob. Nest J. 16, 463-473.

Chong, M.N., Jin, B., Chow, C.W., Saint, C., 2010. Recent developments in photocatalytic water treatment technology: a review. Water Res. 44, 2997-3027.

Dalrymple, O.K., Yeh, D.H., Trotz, M.A., 2007. Removing pharmaceuticals and endocrine-disrupting compounds from wastewater by photocatalysis. J. Chem. Technol. Biotechnol. 82, 121-134.

Fatta-Kassinos, D., Meric, S., Nikolaou, A., 2011. Pharmaceutical residues in environmental waters and wastewater: current state of knowledge and future research. Anal. Bioanal. Chem. 399, 251-275.

Halling-Sorensen, B., Nielsen, S.N., Lanzky, P.F., Ingerslev, F., Lutzhoft, H.C.H., Jorgensen, S.E., 1998. Occurrence, fate and effects of pharmaceutical substances in the environment - a review. Chemosphere 36, 357-394.

Hernando, M.D. Mezcua, M. Fernandez-Alba, A.R., Barcelo, D., 2006. Environmenta risk assessment of pharmaceutical residues in wastewater effluents, surface waters and sediments. Talanta 69, 334-342.
Hoffmann, M.R., Martin, S.T., Choi, W.Y., Bahnemann, D.W., 1995. Environmental applications of semiconductor photocatalysis. Chem. Rev. 95, 69-96.

Ji, Y., Zhou, L., Ferronato, C., Yang, X., Salvador, A., Zeng, C., Chovelon, J.-M., 2013. Photocatalytic degradation of atenolol in aqueous titanium dioxide suspensions: kinetics, intermediates and degradation pathways. J. Photochem. Photobiol. A Chem. 254, 35-44.

Joss, A., Zabczynski, S., Gobel, A., Hoffmann, B., Loffler, D., McArdell, C.S., Ternes, T.A., Thomsen, A., Siegrist, H., 2006. Biological degradation of pharmaceuticals in municipal wastewater treatment: proposing a classification scheme. Water Res. 40, 1686-1696.

Lee, S.Y., Park, S.J., 2013. $\mathrm{TiO}_{2}$ photocatalyst for water treatment applications. J. Ind. Eng. Chem. 19, 1761-1769.

Lettmann, C., Hinrichs, H., Maier, W.F., 2001. Combinatorial discovery of new photocatalysts for water purification with visible light. Angew. ChemieInternational Ed. 40, 3160.

Lin, C.-F., Shiu, Y.-J., Kuo, C.-S., Lin, A.-C., Wu, C.-H., Hong, P.-K., 2013. Photocatalytic degradation of morphine, methamphetamine, and ketamine by illuminated $\mathrm{TiO}_{2}$ and ZnO. Reaction Kinetics. Mech. Catal. 110, 559-574.

Malato, S., Blanco, J., Alarcon, D.C., Maldonado, M.I., Fernandez-Ibanez, P., Gernjak, W., 2007. Photocatalytic decontamination and disinfection of water with solar collectors. Catal. Today 122, 137-149.

Matsuo, S., Sakaguchi, N., Yamada, K., Matsuo, T., Wakita, H., 2004. Role in photocatalysis and coordination structure of metal ions adsorbed on titanium dioxide particles: a comparison between lanthanide and iron ions. Appl. Surf. Sci. 228, 233-244.

Merabet, S., Bouzaza, A., Wolbert, D., 2009. Photocatalytic degradation of indole in a circulating upflow reactor by $\mathrm{UV} / \mathrm{TiO}_{2}$ process - influence of some operating parameters. J. Hazard. Mater. 166, 1244-1249.

Radjenovic, J., Petrovic, M., Ventura, F., Barcelo, D., 2008. Rejection of pharmaceuticals in nanofiltration and reverse osmosis membrane drinking water treatment. Water Res. 42, 3601-3610.

Romao, J., Barata, D., Habibovic, P., Mul, G., Baltrusaitis, J., 2014. High throughput analysis of photocatalytic water purification. Anal. Chem. 86, 7612-7617.

Romão, J.S., Hamdy, M.S., Mul, G., Baltrusaitis, J., 2015. Photocatalytic decomposition of cortisone acetate in aqueous solution. J. Hazard. Mater. 282, 208-215.

Ryu, J., Choi, W., 2007. Substrate-specific photocatalytic activities of $\mathrm{TiO}_{2}$ and multiactivity test for water treatment application. Environ. Sci. Technol. 42, 294-300.

Sigma-Aldrich, LOPAC@1280-The Library of Pharmacologically Active Compounds.

Spasiano, D., Marotta, R., Malato, S., Fernandez-Ibañez, P., Di Somma, I., 2015. Solar photocatalysis: materials, reactors, some commercial, and pre-industrialized applications. A comprehensive approach. Appl. Catal. B Environ. 170-171, 90-123.

Xiao, H.Y., Dai, Q.X., Li, W.S., Au, C.T., Zhou, X.P., 2006. Photo-degradation catalyst screening by high throughput experiments. J. Mol. Catal. a-Chemical 245, $17-25$. 